\title{
A Prospective Study on the Outcome of Semi-Closed Neurointensive Care in A Tertiary Care Hospital Located in A Rural Area of Eastern Nepal: A Lower-Income Developing Country.
}

\author{
Niraj Kumar Keyal' ${ }^{1}$, Pankaj Raj Nepal ${ }^{2}$, Karuna Tamrakar ${ }^{2}$, Robin Bhattarai ${ }^{2}$, Dinesh Kumar \\ Thapa $^{2}$, Rupesh Kumar Chaurasiya ${ }^{1}$
}

\author{
${ }^{1}$ Department of Critical Care Medicine, B \& C Medical College, Teaching Hospital andResearch Center, \\ Birtamode, Nepal \\ ${ }^{2}$ Department of Neurosurgery, B \& C Medical College, Teaching Hospital and Research Center, Birtamode, \\ Nepal \\ Correspondence: \\ Dr Niraj Kumar Keyal \\ Department of Critical Care Medicine \\ B\&C Medical College Teaching Hospital and Research Center, Birtamode. \\ Phone No: +977 9855027141 \\ Email: nirajkumarkeyal@gmail.com
}

\begin{abstract}
Background: High mortality and morbidity in neurological patients are found due to lack of closed ICU (Intensive Care Unit), neurointensivist, and training in neurocritical care in most of the developing countries. Therefore, this study was conducted to evaluate the outcome of the neurological patient managed by neurointensivist in a semi-closed ICU.Materials and methods: It was a prospective, descriptive observational cross-sectional study in a level three Neuro-intensive care unit of a tertiary care hospital of Eastern Nepal, for one year in 191 patients. All patients above 18 years admitted to the Neuro-intensive care unit were included in this study. Demographic data was collected for all patients at the time of presentation to the ICU. The outcome of the patient was defined as transferred to Neuro-Ward, leave against medical advice (LAMA), do not resuscitate (DNR) and death. Statistical analysis was done by using SPSS. The result was presented as frequency and percentage.Results: Out of 191 patients, Males $(71.7 \%)$ was more common than females (28.2\%). There were 107 (56\%) patients were admitted after 24 hours of injury or illness. 28.2\% of patients had a hemorrhagic stroke and was the most common diagnosis for admission in the ICU. This study showed that $58(82.72 \%)$ patients survived and were discharged, $23(12 \%)$ expired, $7(3.66 \%)$ went in LAMA) and $3(1.57 \%$ ) gave do not resuscitate orders (DNR). Mean days on a mechanical ventilator was $3.17 \pm 2.12$ days. Mortality in the intubated patient was $19 \%$.Conclusion: A semi-closed Neuro-intensive care unit that includes full-time neurointensivist may have a better outcome than the open ICU.
\end{abstract}

Key words: Developing country, Intensive Care Units, Neurocritical care, Neurosurgery

$\mathrm{N}$ eurological diseases affect 276 million people worldwide, which constitute $11.6 \%$ of the global burden and cause $16.5 \%$ of global death. ${ }^{1}$ There is a lack of data on the incidence of neurological disorder in Nepal but in other developing countries like India, Pakistan, and
Nigeria it ranges from $2.5-5 \% .^{2-4}$ Life expectancy has increased in most of the developing countries and in Nepal it has increased by 12.16 years since 1990, reaching 70.64 years in 2013 for both sex. ${ }^{4}$ High life expectancy has increased the number of older population which in turn has escalated the 
people with neurological disorders in the world, which is also the same in Nepal and other developing countries. ${ }^{5-8}$

There is a lack of Intensive care unit (ICU) care in Nepal, and moreover there is more shortage of ICU beds in rural areas of Nepal. Data on the status of ICU across the country is also insufficient. However, a phone survey conducted in Kathmandu valley showed that there were roughly 480 ICU beds with 260 ventilators. ${ }^{9}$ There has been no data available on the number of ICU which is closed, semi-closed, or open. However, most of them are open.

Neurological patients account for $30-40 \%{ }^{10-14}$ of total admissions in the ICU. Studies have shown that neurological patient managed by neurointensivist in a closed ICU has a better outcome. $^{15-17}$ Increasing requirement of the intensivist, lack of political commitment and public awareness has led to difficulty in establishing closed ICU in a developing country like Nepal. Semi-closed ICU managed by a full-time intensivist, neurosurgeon, neuro physician can be an alternative option. High mortality and morbidity in neurological patients are found due to lack of closed ICU, neurointensivist, and training in neurocritical care in most of the developing countries. Therefore, this study was conducted to evaluate the outcome of the neurological patient managed by neurointensivist in a semi-closed ICU.

\section{Methods and Materials:}

Study design and population: We conducted a prospective, descriptive observational crosssectional study in a level three Neuro-intensive care unit of tertiary care hospital of Eastern Nepal between Baishakh 1, 2076 to Chaitra 30, 2076. Ethical approval from the Institutional Review Committee was obtained before enrolment in this study. Written informed consent was obtained from the patients or surrogate decision-makers.

All patients above 18 years admitted to the neurointensive care unit were included in this study. Patients were excluded if they were younger than 18 years, surrogate decision-maker, or patient did not give written informed consent and were not having a neurological disease.
Data collection: Clinical data collected included Age, Sex, Occupation, Ethnicity, Acute Physiology, And Chronic Health Evaluation (APACHE) II, Sequential Organ Failure Assessment (SOFA) Score, Injury severity score, Diagnosis, Intubated or Non-intubated, Specialty, Sub-specialty, Co-morbidity, Time lag between injury or symptom and presentation to the ICU, mode of admission in ICU.

The outcome of the patient was defined as leave against medical advice (LAMA), do not resuscitate (DNR), death, and transferred to ward. The patient admitted to the neuro-intensive care unit who wishes to leave against the clinicians' advice was referred to as leave against medical advice (LAMA). Patients who were given all treatment except cardiopulmonary resuscitation and endotracheal intubation was referred as Do-notresuscitate (DNR) but if signed after CPR and intubation, the patient was kept on ventilator support if the withdrawing of support was not requested. LAMA and DNR order were signed by the surrogate decision-maker after discussing it with the neurocritical care team. The reason for LAMA and DNR was recorded.

The following data was gathered before the patient was shifted to the ward from the neuro-intensive care unit or HDU: days on mechanical ventilation, length of stay in the intensive care unit.

The patient was followed in the ward until they were discharged, referred to another hospital or readmitted to neuro-intensive care unit, the reason for readmission and outcome of the readmitted patients was recorded.

Statistical analysis: Statistical analysis was performed using SPSS software (version 16.0; IBM, SPSS, Chicago, IL, USA). Values are presented as mean ( \pm standard deviation SD) or frequency. 
Keyal NK et al.

\section{Results:}

A total of 702 Patients were admitted to the ICU from $1^{\text {st }}$ of Baishakh 2076 to $30^{\text {th }}$ Chaitra2076.

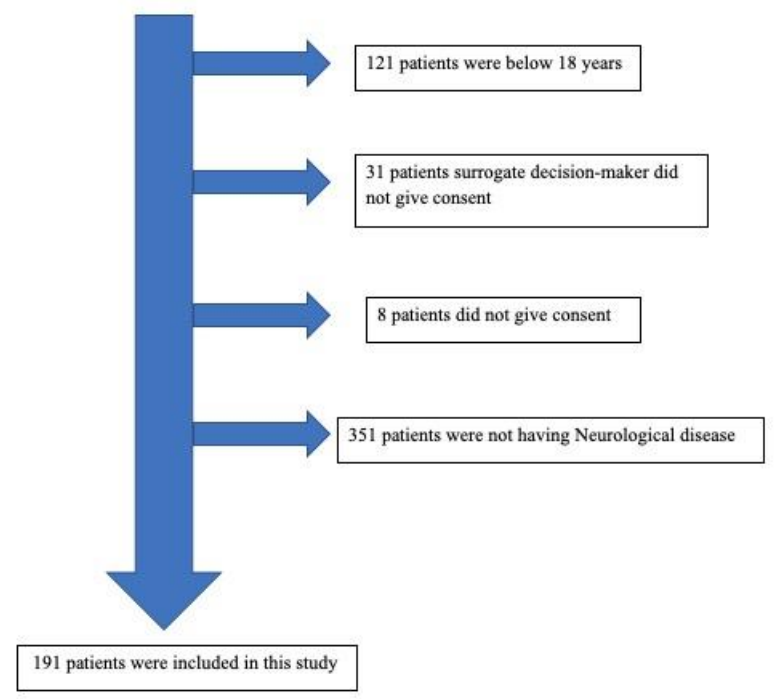

Figure 1. Flow diagram of patients included in this study.

Figure 1 shows that 191 patients were included in this study. The neurological disease accounts for $27.2 \%$ of total admission in the ICU in our study.
Table 1. Demographic characteristics of the study population

\begin{tabular}{|c|c|}
\hline Parameters & n (\%) \\
\hline \multicolumn{2}{|l|}{ Age (Years) } \\
\hline $18-35$ & $55(28.7)$ \\
\hline $36-60$ & $82(42.9)$ \\
\hline$>60$ & $54(28.2)$ \\
\hline \multicolumn{2}{|l|}{ Sex } \\
\hline Male & $137(71.7)$ \\
\hline Female & $54(28.2)$ \\
\hline \multicolumn{2}{|l|}{ Ethnicity } \\
\hline Hindu & $168(87.9)$ \\
\hline Kirat & $15(7.8)$ \\
\hline Buddhist & $5(2.6)$ \\
\hline Muslim & $2(1.0)$ \\
\hline Christian & $1(0.5)$ \\
\hline \multicolumn{2}{|l|}{ Occupation } \\
\hline Unemployed & $64(33.5)$ \\
\hline Farmer & $52(27.2)$ \\
\hline Housewife & $22(11.5)$ \\
\hline Student & 21(10.9) \\
\hline Labour & $6(3.1)$ \\
\hline Businessman & $7(3.6)$ \\
\hline Technical worker & $15(7.8)$ \\
\hline Army & $4(2.0)$ \\
\hline
\end{tabular}

Table 1 shows the demographics characteristics of the study population. Middle-age patients were admitted more than younger and older age patients. $137(71.7 \%)$ were males and 54(28.2\%) were females. Most of the patients in this study were Hindus and unemployed. 
Table 2: Clinical characteristics of the study population

\begin{tabular}{|c|c|}
\hline Parameters & $\mathrm{n}(\%)$ \\
\hline \multicolumn{2}{|l|}{ Diagnosis } \\
\hline Non-Trauma & $98(51.3)$ \\
\hline Trauma & 93(48.6) \\
\hline
\end{tabular}

Injury severity score

$\begin{array}{ll}<15 & 63(67.7) \\ >15 & 30(32.2)\end{array}$

APACHE II Score at the time of admission

$\begin{array}{cc}3-10 & 125(65.4) \\ 11-20 & 56(29.3) \\ 21-30 & 9(4.7) \\ 31-40 & 1(0.5)\end{array}$

SOFA Score at the time of admission

$\begin{array}{cc}0-6 & 173(90.5) \\ 7-12 & 15(7.8) \\ 13-18 & 2(1.0) \\ 19-24 & 1(0.5)\end{array}$

Time of presentation to ICU (Hours)

$\begin{array}{cc}<6 & 25(13.0) \\ 6-12 & 23(12.0) \\ 12-24 & 36(18.8) \\ >24 & 107(56.0)\end{array}$

Mode of admission in ICU

$\begin{array}{lc}\text { Direct } & 37(19.3) \\ \text { Refer } & 152(79.5) \\ \text { Ward } & 2(1.0)\end{array}$

Group of patient

$\begin{array}{cc}\text { Intubated } & 63(32.9) \\ \text { Non-Intubated } & 128(67.0)\end{array}$

\footnotetext{
APACHE II: Acute physiology and chronic health evaluation, ICU: Intensive care unit, SOFA: Sequential organ failure assessment.
}

Table 2 shows the clinical characteristics of the study population. Non-trauma patients were more 10 common than trauma patients. There were $63 \%$ of trauma patients with injury severity score of less than 15 . The majority of the patient at the time of admission had APACHE II of 3-10 and SOFA scores of 0-6. Most patients were admitted after 24 hours of injury or illness, referred from other hospitals and non-intubated.

This study showed that $159(83.24 \%)$ patients survived and were shifted to ward, 23(12\%) expired, 6(3\%) LAMA and 3(1.57\%) DNR. One hundred fifty-nine patients survived and were shifted to the ward or high dependency unit.

Two $(1.25 \%)$ patients got readmitted to the ICU. Neurological impairment was the most common reason for readmission in the ICU. Out of 2 patients, $1(50 \%)$ was shifted to a ward, and others went in LAMA.

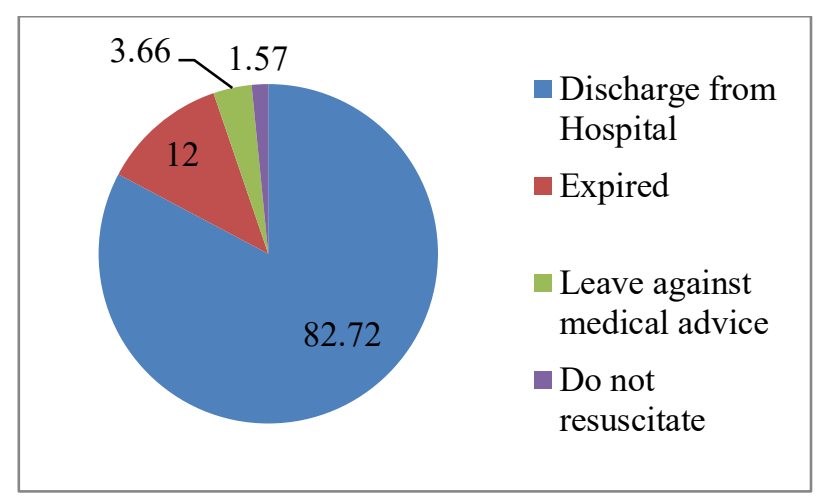

Figure 2: Outcome of patients from the hospital that were admitted to the intensive care unit.

Figure 2 shows the outcome of patients from the hospital that was admitted to the neuro-intensive care unit.

Our study showed that $158(82.72 \%)$ patients survived and were discharged, 23(12\%) expired, $7(3.66 \%)$ went in LAMA and 3(1.57\%) gave DNR consent.

The mortality rate in our study was $23(12 \%)$. $14(60.8 \%)$ expired after 48 hours of ICU admission and $9(39.1 \%)$ within 48 hours of ICU admission.

Out of 191 patients, 63(32.9\%) were intubated and required mechanical ventilation. The minimum days on a mechanical ventilator were 1 day and the maximum was 10 days. Mean days on a egneuro, Volume 02, Issue 03, 2020 
Keyal NK et al.

mechanical ventilator was $3.17 \pm 2.12$ days. Mortality in the intubated patient was 19\%.

The minimum length of stay (LOS) for all groups of patients in the ICU was 1 day and the maximum was 29 days.

In our study poor prognosis and the high cost were the reason for LAMA in $5(71.4 \%)$ and $2(28.6 \%)$ patients respectively.

Table 3. The outcome of patients according to sub-specialty

\begin{tabular}{cccccc}
\hline $\begin{array}{c}\text { Sub- } \\
\text { specialty }\end{array}$ & $\begin{array}{c}\text { Discharged } \\
\mathbf{n}(\%)\end{array}$ & $\begin{array}{c}\text { LAMA } \\
\mathbf{n}(\%)\end{array}$ & $\begin{array}{c}\text { DNR } \\
\mathbf{n}(\%)\end{array}$ & $\begin{array}{c}\text { Expired } \\
\mathbf{n}(\%)\end{array}$ & $\begin{array}{c}\text { Total } \\
\mathbf{n}(\%)\end{array}$ \\
\hline Neurology & $31(59.6)$ & $5(9.6)$ & $2(3.8)$ & $14(26.9)$ & $52(100)$ \\
Neurosurgery & $127(91.3)$ & $2(1.4)$ & $1(0.7)$ & $9(6.4)$ & $139(100)$ \\
& $158(82.72 \%)$ & $7(3.66 \%)$ & $3(1.57 \%)$ & $23(12)$ & $191(100)$ \\
\hline
\end{tabular}

DNR: Do Not Resuscitate, LAMA: Leave Against Medical Advice.

Table 3 shows the outcome of patients according to sub-specialty.

Table 4. The outcome of patients according to diagnosis

\begin{tabular}{|c|c|c|c|c|c|}
\hline $\begin{array}{l}\text { Primary } \\
\text { diagnosis }\end{array}$ & $\begin{array}{c}\text { Discharged } \\
\mathbf{n}(\%)\end{array}$ & $\begin{array}{l}\text { LAMA } \\
\text { n(\%) }\end{array}$ & $\begin{array}{l}\text { DNR } \\
\text { n(\%) }\end{array}$ & $\begin{array}{l}\text { Expired } \\
\mathbf{n}(\%)\end{array}$ & $\begin{array}{l}\text { Total } \\
\mathbf{n}(\%)\end{array}$ \\
\hline Brain tumor & $6(100)$ & 0 & 0 & 0 & $6(100)$ \\
\hline Cranioplasty & $4(100)$ & 0 & 0 & 0 & $4(100)$ \\
\hline $\begin{array}{l}\text { Diffuse } \\
\text { axonal injury }\end{array}$ & $8(100)$ & 0 & 0 & 0 & $8(100)$ \\
\hline $\begin{array}{l}\text { Epidural } \\
\text { hematoma }\end{array}$ & $28(96.5)$ & $1(3.4)$ & 0 & 0 & $\begin{array}{l}29(10 \\
0)\end{array}$ \\
\hline $\begin{array}{l}\text { Guillain } \\
\text { barre }\end{array}$ & $2(100)$ & 0 & 0 & 0 & $2(100)$ \\
\hline syndrome & & & & & \\
\hline $\begin{array}{l}\text { Hemorrhagic } \\
\text { stroke }\end{array}$ & $40(83.3)$ & $1(2.0)$ & $1(2.0)$ & $6(12.5)$ & $\begin{array}{c}48(10 \\
0)\end{array}$ \\
\hline $\begin{array}{l}\text { Hypoxic } \\
\text { brain injury }\end{array}$ & 0 & 0 & 0 & $1(100)$ & $1(100)$ \\
\hline Ischemic & $18(64.2)$ & $2(7.1)$ & $1(3.5)$ & $7(25.0)$ & $\begin{array}{l}28(10 \\
0)\end{array}$ \\
\hline
\end{tabular}

\begin{tabular}{llllll} 
stroke & & & & & \\
Meningoence & $2(22.2)$ & $2(22.2)$ & $1(11.1)$ & $4(44.4)$ & $9(100)$ \\
phalitis & & & & & \\
Neurocystice & $2(100)$ & 0 & 0 & 0 & $2(100)$ \\
rcosis & & & & & \\
Subdural & $20(86.9)$ & 0 & 0 & $3(13.0)$ & $23(10$ \\
hematoma & & & & & $0)$ \\
Seizure & $4(66.6)$ & $1(16.6)$ & 0 & $1(16.6)$ & $6(100)$ \\
disorder & & & & & \\
Skull bone & $9(100)$ & 0 & 0 & 0 & $9(100)$ \\
fracture & & & & & \\
Spinal cord & $12(100)$ & 0 & 0 & 0 & $12(10$ \\
injury & & & & & 0 \\
Tetanus & $3(75.0)$ & 0 & 0 & $1(25.0)$ & $4(100)$ \\
Total & $158(82.7)$ & $7(3.6)$ & $3(1.5)$ & 23 & 191 \\
& & & & & \\
\hline
\end{tabular}

Table 4 shows the outcome of patients according to diagnosis. Our study showed $28.2 \%$ of patients had a hemorrhagic stroke and was the most common diagnosis for admission in the ICU and $83.3 \%$ of patients were shifted to the ward. $100 \%$ of patients recovered from a brain tumor, cranioplasty, diffuse axonal injury, neurocysticercosis, skull bone fracture, and spinal cord injury.

Out of 191 patients, 93(48.6\%) of patients had a traumatic brain injury (TBI). $87(93.5 \%)$ patients were shifted to ward, $4(4.3 \%)$ expired, $1(1 \%)$ LAMA, and $1(1 \%)$ gave DNR consent.

\section{Discussion:}

The incidence of neurological disease that required ICU admission in our study was $27.2 \%$ while in the other studies it varied from $30-40 \% .{ }^{10-14}$ The lower incidence in our study may be due to geographical variation and people from all communities may not afford a private hospital for treatment.

The present study showed that the incidence of neurosurgical and neurology patients that required ICU admission was $72.7 \%$ and $27.2 \%$ respectively. 
Keyal NKet al.

Most of the neurosurgery patients present as emergency cases requiring immediate surgical interventions requiring ICU care, rendering to the high rate of such patients in our study.

The present study has shown that cerebrovascular disease was the most common reason for admission of patients in the ICU which is similar to other studies. ${ }^{18-20}$ This may be because the cerebrovascular disease is an emergency requiring ICU care while other diseases may present as a non-emergency condition.

In present study, mortality was $12 \%$ while in other studies it varied from $4.5 \%$ to $10 \%{ }^{15-17}$ The difference may be due to a lack of early resuscitation in rural areas before the transportation of patients to tertiary care.

Mortality in the intubated patients was $19 \%$ while in other studies varied from 25 to $40 \%$. ${ }^{10-14,19-}$

${ }^{21}$ This difference may be due to the co-management of patients by neurointensivist in our study.

The readmission rate in our study was $1.25 \%$ and $50 \%$ patient recovered and was transferred to ward while in other studies readmission was $10-12 \% .^{10-14}$ Mortality in neurosurgical patients was $6.4 \%$ while in other studies it varied from $10.5-40 \% .{ }^{11,19-21} \mathrm{In}$ present study, LAMA in neurosurgical patients was $1.4 \%$ while in a study by Acharya et $\mathrm{al}^{21}$ it was $7.03 \%$. In our study, DNR in neurosurgical patients was $0.7 \%$ while in a study by Acharya et $\mathrm{al}^{21}$ it was $4.5 \%$. This difference may be due to the early recognition of high-risk patients and early communication with family members. Mortality in TBI was $4.3 \%$ while in other studies it varied from $10.5 \%$ to $30 \%$. ${ }^{19-22}$ This difference may be due to early intervention by a neurosurgeon, the presence of neurointensivist, different geographical conditions, and a small group of trauma patients in our study. Male $(71.7 \%)$ was more common than females $(28.2 \%)$ in this study which is similar to other studies. ${ }^{10-14,19-21}$

The limitations of our study are primarily related to small sample size. Glasgow outcome scale was not recorded so long term of a patient was not known. Our results pertain to a single-center experience which limits generalizability.
A semi-closed ICU that includes full-time neurointensivist may have a better outcome than open ICU and can be a model in a developing country.

\section{References:}

1. GBD 2016 Neurology Collaborators. Global, regional, and national burden of neurological disorders, 1990-2016: a systemic analysis for the Global Burden of Disease Study 2016. Lancet Neurol 2019;18(5):459-80.

2. Gourie-Devi M. Epidemiology of neurological disorders in India: review of background, prevalence and incidence of epilepsy, stroke, Parkinson's disease and tremors. Neurol india 2014;62(6)588-98.

3. Akbar W, Khosa NA, Nasar AB. Burden and pattern of neurological diseases seen in neurology department of a tertiary care hospital in Baluchistan. Pakistan J Neurological Sciences 2017;12(4):5-8.

4. Kaddumukasa M, Mugenyi L, Kaddumukasa MN, Ddumba E, Devereaux M, etal.Prevalence and incidence of neurological disorders among adult Ugandans in rural and urban Mukono district.BMC Neurol.2016;16(1):227

5. GBD 2013 Mortality and Causes of Death Collaborators. Global, regional, and national age-sex specific all-cause and cause specific mortality for 240 causes of death, 19902013: a systemic analysis for the Global Burden of Disease Study 2013. Lancet 2015;385(9963):117-71.

6. Hofman A, de Jong PT, van Dulin CM, Breteler MM. Epidemiology of neurological diseases in elderly people: what did we learn from the Rotterdam Study. Lancet Neurol 2006;5(6):545-50.

7. Asekomeh EGP, OnWuchekwa AC, Iyagba MA. The Burden of Neurological Disease in a Geriatric Population of a Developing Country. African Journal of Neurological Sciences 2009:28(2):73-78

8. Dumurgier J, Tzourio C. Epidemiology of neurological diseases in older adults. Rev Neurol (Paris) 2020: S00353787(20)30390-8.

9. Paneru HR. Intensive care units in the context of COVID19 in Nepal: current status and need of the hour.Journal of Society of Anesthesiologists of Nepal(JSAN) 2020;7(1):e291.

10. Acharya SP, Bhattarai A, Bhattarai B. An Audit of An Intensive Care Unit of A tertiary Care Hospital. JNMA; J Nepal Med Assoc 2018;56(212):759-62.

11. Osinaike BB, Sanusi AA, Ogunsiji AO. A review of neurosurgical admission in a Nigerian intensive Care Unit. J Clin Sci 2018; 15:132-5.

12. Poluyi EO, FadiranOO,PoluyiCO,FalohunSA.Profile of Intensive Care Unit Admissions and Outcomes in a Tertiary Care Center of a Developing Country in West Africa:A 5 Year Analysis.J Intensive Crit Care.2016;2:1-7.

13. Khanduri S, Katiyar S, Kishore N, Sodhi R, Aggarwal A. Retrospective review of profile of intensive care unit admissions and outcomes in a tertiary care hospital of Himalayan region. IJRMS 2017;5(11):4715-8.

\section{Conclusion:}


14. Hamal A B, Hyoju S, Rana S, Shah J.Patients Presenting in Intensive Care Unit of Nepal Police Hospital. J Anest\&Inten Care Med 2019;9(2):0037-40.

15. Ko Ma,Lee JH, Kim JG, Jeong S, Kang DW, Lim CM et al.Effects of Appointing a Full-Time Neurointensivist to Run a Closed-Type Neurological Intensive Care Unit. J Clin Neurol 2019;15(3):360-8.

16. Ryu JA, Yang JH, Chung CR, Suh GY, Hong SC.Impact of Neurointensivist Co-management on the Clinical Outcomes of Patients Admitted to a Neurosurgical IntensiveCare Unit. J Korean Med Sci.2017;32(6):1024-30

17. Suarez JI, Zaidat OO, Suri MF, Feen ES, Lynch G, Hickman J, etal. Length of stay and mortality in neurocritically ill patients: impact of a specialized neurocritical care team. Crit Care Med.2004;32(11):23117.

18. Pokharel BR, Shrestha H, Amatya SR. Spectrum of Neurological Diseases in tertiary care centre of Nepal. NJNS2019;16(3):58-61.

19. Karmacharya B, Yogi N, Baral P. Factors affecting mortality in neurosurgical ICU of Manipal Teaching Hospital, Pokhara, Nepal. Nepal Journal of Medical Sciences 2019;4(2):25-31.

20. Roka YB, Dhungana S, Shrestha M, Chaudhary A, Puri PR, Aryl S et al. Profile of admission to neurosurgical intensive care unit: experience from the only centre in Eastern Nepal. Postgrad Med J NAMS 2011; 11:62-5.

21. Acharya SP, Bhattarai B, Bhattarai A, Pradhan S, Sharma MR. Profile of neurosurgical patients in a tertiary level intensive care unit in Nepal. J Nepal Health Res Counc 2018;16(40):336-9.

22. Kafle P, Khanal B, Yadav DK, Poudel D, Karki T, Cherian I. Head injury in Nepal: An institutional based prospective study on clinical profile, management and early outcome of traumatic brain injury in eastern part of Nepal. BJHS 2019;4(2):750-4. 